\title{
Risk Associated with Pulse Pressure on Out-of-Office Blood Pressure Measurement
}

\author{
Yu-Mei Gu ${ }^{a}$ Lucas S. Aparicio ${ }^{b}$ Yan-Ping Liu ${ }^{a} \quad K e i$ Asayamaa, c \\ Tine W. Hansen $^{d}$ Teemu J. Niiranen ${ }^{\mathrm{e}}$ José Boggia $^{f} \quad$ Lutgarde Thijs $^{\mathrm{a}}$ \\ Jan A. Staessen ${ }^{\mathrm{a}, \mathrm{g}}$ \\ aStudies Coordinating Centre, Division of Hypertension and Cardiovascular Rehabilitation, \\ Department of Cardiovascular Sciences, University of Leuven, Leuven, Belgium; \\ bervicio de Clínica Médica, Sección Hipertensión Arterial, Hospital Italiano de Buenos \\ Aires, Buenos Aires, Argentina; ' Tohoku University Graduate School of Pharmaceutical \\ Science and Medicine, Sendai, Japan; ${ }^{d}$ Steno Diabetes Center, Gentofte, Denmark; \\ e Population Studies Unit, Department of Chronic Disease Prevention, National Institute \\ for Health and Welfare, Turku, Finland; ${ }^{f}$ Centro de Nefrología and Departamento de \\ Fisiopatología, Hospital de Clínicas, Universidad de la República, Montevideo, Uruguay; \\ gVitaK Research and Development, Maastricht University, Maastricht, The Netherlands
}

\section{Key Words}

Pulse pressure - Thresholds · Blood pressure measurement · Epidemiology · Cardiovascular diseases

\begin{abstract}
Background: Longitudinal studies have demonstrated that the risk of cardiovascular disease increases with pulse pressure (PP). However, PP remains an elusive cardiovascular risk factor with findings being inconsistent between studies. The 2013 ESH/ESC guideline proposed that PP is useful in stratification and suggested a threshold of $60 \mathrm{~mm} \mathrm{Hg}$, which is $10 \mathrm{~mm} \mathrm{Hg}$ higher compared to that in the 2007 guideline; however, no justification for this increase was provided. Methodology: Published thresholds of PP are based on office blood pressure measurement and often on arbitrary categorical analyses. In the International Database on Ambulatory blood pressure in relation to Cardiovascular Outcomes (IDACO) and the International Database on HOme blood pressure in relation to Cardiovascular Outcome (IDHOCO), we determined outcome-driven thresholds for PP based on ambulatory or home blood pressure measurement, respectively. Results: The main findings were that for people aged $<60$ years, PP did not refine risk stratification, whereas in older people the thresholds were 64 and 76 $\mathrm{mm} \mathrm{Hg}$ for the ambulatory and home PP, respectively. However, PP provided little added predictive value over and beyond classical risk factors.


Gu et al.: Risk Associated with Pulse Pressure on Out-of-Office Blood Pressure Measurement

\section{Introduction}

Pulse pressure (PP), the difference between systolic and diastolic blood pressure, depends on left ventricular ejection, the elasticity of the central arteries, as well as on the timing and intensity of the backward wave originating at reflection sites in the peripheral circulation. PP widens in the elderly as with advancing age, systolic blood pressure continues to rise, whereas the age-related increase in diastolic blood pressure levels off or even reverses in the fifth decade of life [1].

\section{PP as a Cardiovascular Risk Factor}

Previous studies have shown that peripheral PP as measured by conventional sphygmomanometry is an independent risk factor in patients with hypertension [2-5], coronary heart disease [2] or severe renal dysfunction [6], or in different populations [7-12]. However, other studies [13-15] were contradictory in that cardiovascular risk was not associated with PP. Several limitations of previous studies likely contributed to these contradictory findings in the literature. They mostly used the office blood pressure measurement or only recorded fatal endpoints $[6,8,10-14]$, or applied recruitment criteria confined to high-risk patients [2-6, $14]$, a narrow age range $[8,12]$ or elderly $[5,11]$, or reported that the association between outcome and PP was present only in diabetic [10] or treated hypertensive patients [4].

\section{Studies in Patients}

In the International Verapamil SR-Trandolapril Study (INVEST), Bangalore et al. [2] analyzed 22,576 hypertensive patients with coronary artery disease. The relation of the incidence and multivariable-adjusted hazard ratio (HR) for all-cause mortality, nonfatal myocardial infarction and nonfatal stroke with PP during follow-up was J- or U-shaped. When adjusted for baseline covariables, both the linear and quadratic terms of PP were significant ( $\mathrm{p}<0.0001$ ) [2]. The nadir was at $54 \mathrm{~mm} \mathrm{Hg}$, with the $95 \%$ confidence interval (CI) derived by bootstrapping ranging from 42 to $60 \mathrm{~mm} \mathrm{Hg}$ [2]. The relation of stroke with PP was linear [2].

Greenberg [4] analyzed 2,939 hypertensive patients aged 33-87 years enrolled in the Epidemiologic Follow-Up Study (NHEFS) of the First National Health and Nutrition Examination Survey (NHANES I). For cardiovascular mortality, the HRs associated with a 10-mm $\mathrm{Hg}$ increment in PP were 1.16 (95\% CI, 1.08-1.25) and 1.12 (95\% CI, 0.99-1.26) in treated and untreated hypertensive patients, respectively [4]. In the Systolic Hypertension in the Elderly Program (SHEP), Domanski et al. [5] demonstrated that with a 10-mm Hg increase in PP, the risk of all-cause mortality and that of fatal stroke increased by 16 and 11\%, respectively.

\section{Studies in Populations}

In 2001, Framingham Heart Study, Franklin et al. [7] reported that with increasing age, there was a gradual shift from diastolic to systolic blood pressure and then to PP as predictors of coronary heart disease in the Framingham Heart Study. In 1989, Darne et al. [12] evaluated the risk associated with PP and mean arterial pressure, while addressing the colinearity between these two predictive variables. They used principal components analysis of systolic and diastolic blood pressure to generate a pulsatile and a steady component index of arterial pressure. The pulsatile component index was positively correlated with PP and the steady component index with mean arterial pressure; however, in statistical terms, the two new indices were completely unrelated. In 18,336 men and 9,351 women aged 40-69 years who 
Gu et al.: Risk Associated with Pulse Pressure on Out-of-Office Blood Pressure Measurement

were followed for an average of 9.5 years, the investigators demonstrated that the steady component index of blood pressure was a strong predictor of all types of cardiovascular death in both sexes [12]. In contrast, the pulsatile component index was unrelated to prognosis in men, whereas in women it was positively and independently correlated with death from coronary heart disease and inversely correlated with stroke mortality [12]. However, the latter relations in women were based only on 15 deaths from myocardial infarction and on 22 deaths from stroke [12].

Along similar lines, Benetos et al. [8] recruited 19,083 French men aged 40-69 years at baseline and followed them for 19.5 years. A wide PP was an independent and significant predictor of all-cause mortality (odds ratio for a $10-\mathrm{mm} \mathrm{Hg}$ increase in younger participants vs. older participants, 1.28 vs. $1.19 ; \mathrm{p}<0.05$ ), total cardiovascular mortality (1.36 vs. 1.24 ; $\mathrm{p}<0.05$ ), and especially coronary mortality (1.40 vs. 1.20 ; p < 0.05) [8]. In 1981, the National Institute on Aging initiated its epidemiologic studies of elderly people [11]. Glynn et al. [11] followed 9,431 participants aged 65-102 years for 10.6 years. In a sex- and age-adjusted survival analysis [11], both elevated systolic blood pressure $>160 \mathrm{~mm} \mathrm{Hg}$ and low diastolic blood pressure $<70 \mathrm{~mm} \mathrm{Hg}$ independently predicted total mortality [relative risk, 1.39 (95\% CI, 1.26-1.53) for systolic and 1.27 (95\% CI, 1.16-1.38) for diastolic blood pressure] and cardiovascular mortality [1.59 (95\% CI, 1.39-1.81) for systolic and 1.38 (95\% CI, 1.22-1.55) for diastolic blood pressure; $\mathrm{p}<0.001]$. PP was strongly correlated with systolic blood pressure $(r=0.82)$ [11], confirming the issue of colinearity introduced by Darne et al. [12]. Glynn et al. [11] reported that PP was a slightly stronger predictor of both total mortality [relative risk, 1.34 (95\% CI, 1.23-1.46)] and cardiovascular mortality [1.57 (95\% CI, 1.391.77)]. In contrast, in Japanese population studies, PP was only a weak predictor of stroke [16, 17] and did not predict myocardial infarction [18].

\section{Risk Associated with Out-of-Office PP}

\section{International Database on Ambulatory Blood Pressure in Relation to Cardiovascular}

\section{Outcomes}

To define outcome-driven thresholds for ambulatory PP, we did a subject-level metaanalysis of 9,938 patients recruited from 11 populations and enrolled in the International Database on Ambulatory blood pressure in relation to Cardiovascular Outcomes (IDACO) [19]. Due to the results from the Framingham Heart Study [20] and the lower age boundary in several randomized clinical trials on antihypertensive treatment in the elderly [21], we stratified our analyses by 60 years of age. Exploratory analyses demonstrated that the association of endpoints with 24-hour PP was not always log-linear. To account for this nonlinear association, we applied the deviation from mean coding to compute HRs in deciles of the 24-hour PP distribution. This approach expresses the risk in each decile relative to the overall risk in the whole study population and allows computing 95\% CIs for the HRs in all deciles without the definition of an arbitrary reference group. HRs relating endpoints to mean arterial pressure expressed the risk associated with a 1-SD increase in the level. We applied the generalized $\mathrm{R}^{2}$ statistic to assess the risks additionally explained by 24-hour PP over and beyond mean arterial pressure and other covariables. In an attempt to refine the level of PP that was associated with a significantly increased risk, we performed a stepwise analysis. We calculated HRs for 1-mm Hg increments in PP for thresholds ranging from the 10th to the 90th percentile. These HRs expressed the risk in participants whose PP exceeded the cutoff point versus the average risk. We plotted these HRs and their 95\% CIs versus the increasing cutoff points with the goal to determine at which level the lower confidence limit of the HRs crossed unity. 
Gu et al.: Risk Associated with Pulse Pressure on Out-of-Office Blood Pressure Measurement

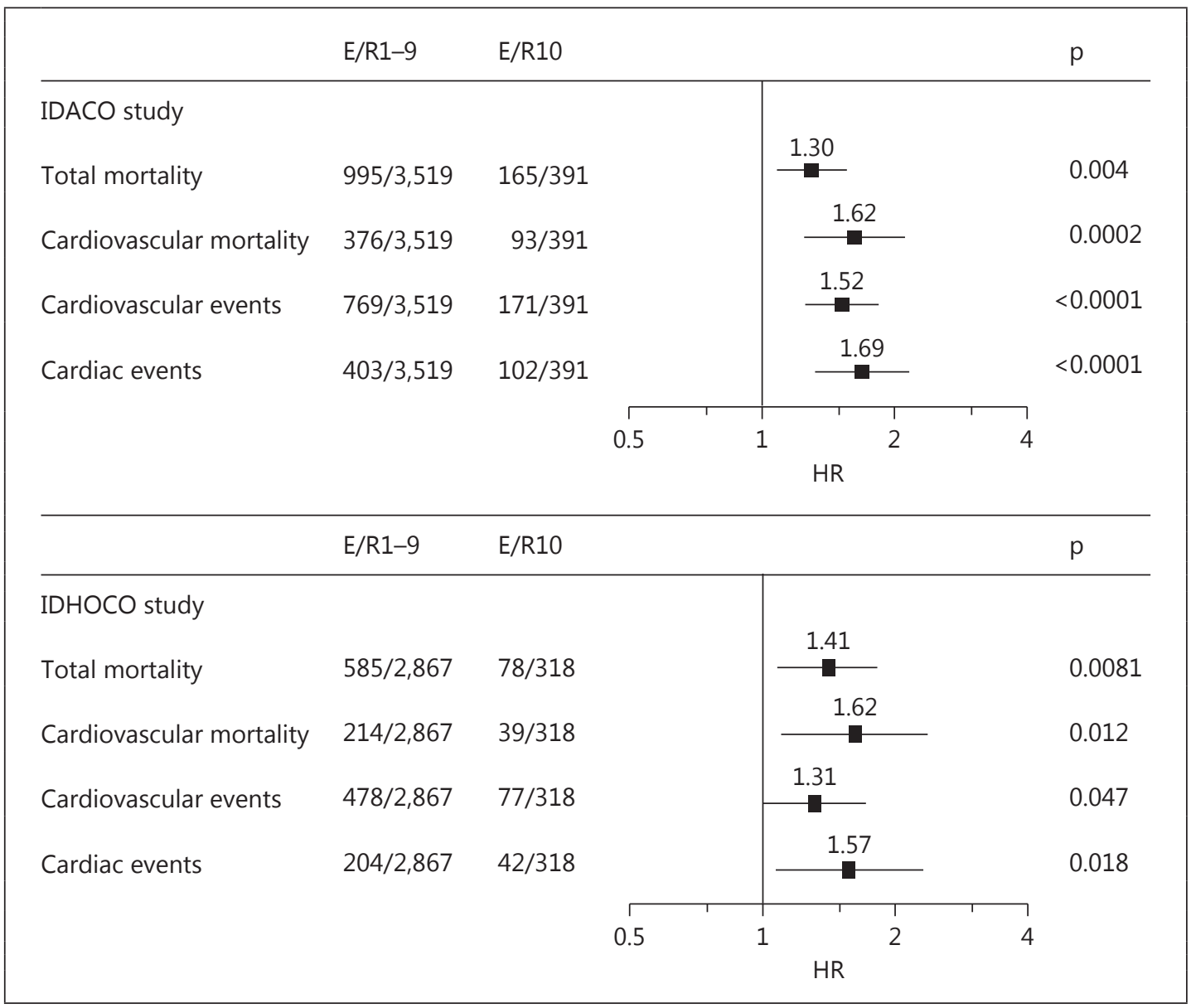

Fig. 1. Multivariable-adjusted HRs for outcomes in relation to 24-hour PP in the IDACO study (a) and to home PP in the IDHOCO study (b). The HRs, presented with 95\% CIs, express the risk in the top decile compared with the average risk in the participants. All models were adjusted for cohort, sex, age, mean arterial pressure and pulse rate, body mass index, smoking and drinking, serum cholesterol, history of cardiovascular disease and diabetes, and antihypertensive drug treatment. The $\mathrm{p}$ values are for the risk in the top decile relative to the overall risk in the whole study population. E/R1-9 = Number of events and participants at risk below the 90th percentile of the PP distribution. E/R10 = Number of events and participants at risk in the top decile, respectively. Reproduced with permission from Gu et al. [19] and Aparicio et al. [22].

In the 6,028 younger participants ( $<60$ years), the median follow-up was 12.1 years. Over 68,853 person-years, 228 participants died and 221 experienced a fatal or nonfatal cardiovascular complication. Only in the highest decile of the PP distribution (threshold, $\geq 55.6 \mathrm{~mm}$ $\mathrm{Hg}$; mean, $60.1 \mathrm{~mm} \mathrm{Hg}$ ) the risk of the composite cardiovascular endpoint was elevated [HR, $1.58(95 \% \mathrm{CI}, 1.11-2.25) ; \mathrm{p}=0.011]$ with a similar trend for cardiac endpoints [HR, 1.52 (95\% CI, 0.99-2.33); $p=0.056]$. Otherwise, the risks across deciles of the PP distribution did not deviate from the average risk ( $p \geq 0.058)$. For stroke, Cox models across deciles of the PP distribution did not converge because of the low number of events $(n=63)$. While calculating the thresholds of 24-hour PP levels that stepwise increased by $1 \mathrm{~mm} \mathrm{Hg}$ from the 10th to the 90th percentile, for all endpoints under study, the lower boundary of the 95\% CIs of the successive HRs did not cross unity.

In the 3,910 older participants ( $\geq 60$ years), the median follow-up was 10.7 years. Over 39,923 person-years, 1,160 participants died and 940 experienced a fatal or nonfatal cardio- 
Gu et al.: Risk Associated with Pulse Pressure on Out-of-Office Blood Pressure
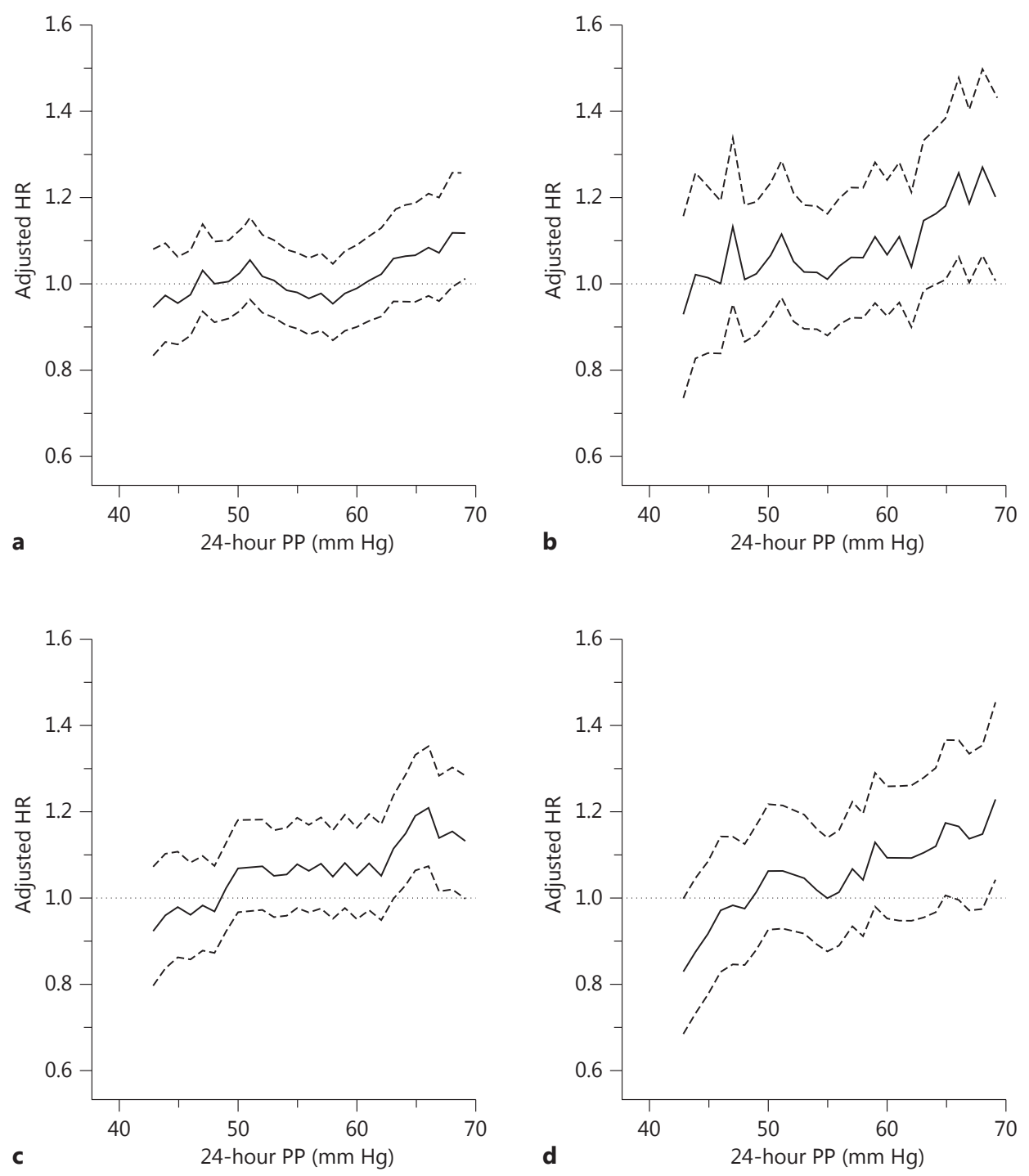

Fig. 2. HRs according to 24-hour PP levels ranging from the 10 th to the 90 th percentile in 3,910 older participants. HRs for all-cause (a) and cardiovascular (b) mortality as well as for cardiovascular (c) and cardiac (d) events express the risk at each level of PP compared with the average risk. Solid and dotted lines denote the point estimates and the $95 \%$ CIs, respectively. The HRs were adjusted as in figure 1 . Reproduced with permission from Gu et al. [19].

vascular complication. The risk of any death, cardiovascular mortality, a composite cardiovascular endpoint, or a cardiac event was consistently elevated in the top decile of the PP distribution (threshold, $\geq 68.8 \mathrm{~mm} \mathrm{Hg}$; mean, $76.1 \mathrm{~mm} \mathrm{Hg}$; fig. 1). The HRs were 1.30 for allcause mortality, 1.62 for cardiovascular mortality, 1.52 for a composite cardiovascular endpoint, and 1.69 for a cardiac event (fig. 1). The HR for stroke in the top decile of the PP distribution was $1.40(p=0.028)$. Otherwise, the risks across the deciles of the PP distribution did not deviate from the average risk. The $\mathrm{R}^{2}$ statistic for adding a design variable coding for the top decile of the 24-hour PP distribution to Cox models including all other covariables was 
Gu et al.: Risk Associated with Pulse Pressure on Out-of-Office Blood Pressure Measurement

Table 1. Characteristics of 24-hour PP by age group and blood pressure status

\begin{tabular}{lcccc}
\hline Characteristic & Normotension & $\begin{array}{l}\text { White-coat } \\
\text { hypertension }\end{array}$ & $\begin{array}{l}\text { Masked } \\
\text { hypertension }\end{array}$ & $\begin{array}{l}\text { Sustained } \\
\text { hypertension }\end{array}$ \\
\hline$<60$ years $(\mathrm{n}=6,028)$ & $4,189(69.5)$ & $430(7.1)$ & $605(10.1)$ & $804(13.3)$ \\
$\quad$ Participants & $44.8 \pm 5.9$ & $47.2 \pm 5.8$ & $50.0 \pm 8.8$ & $51.8 \pm 8.8$ \\
24-hour PP, mm Hg & $1,403(35.9)$ & $655(16.7)$ & $481(12.3)$ & $1,371(35.1)$ \\
$\geq 60$ years $(\mathrm{n}=3,910)$ & $48.6 \pm 6.4$ & $51.3 \pm 6.3$ & $58.6 \pm 9.0$ & $62.7 \pm 10.7$ \\
$\quad$ Participants & $16(0.41)$ & $15(0.38)$ & $112(2.86)$ & $562(14.4)$ \\
24-hour PP, mm Hg & PP level $\geq 64$ mm Hg & & & \\
\hline
\end{tabular}

Values are presented as $\mathrm{n}(\%)$ or mean \pm SD. Conventional hypertension was defined as a conventional blood pressure of $\geq 140 \mathrm{~mm} \mathrm{Hg}$ (systolic) or $\geq 90 \mathrm{~mm} \mathrm{Hg}$ (diastolic). Ambulatory hypertension was defined as a 24-hour blood pressure level of $\geq 130 \mathrm{~mm} \mathrm{Hg}$ (systolic) or $\geq 80 \mathrm{~mm} \mathrm{Hg}$ (diastolic). Normotension and sustained hypertension were consistently normal or elevated blood pressure levels on both conventional and ambulatory measurements. White-coat hypertension was conventional hypertesion in the presence of a normal ambulatory blood pressure. Masked hypertension was ambulatory hypertesion in the presence of a normal conventional blood pressure. In participants aged $<60$ years, the analyses did not identify a riskconferring threshold; in older participants the risk of all-cause mortality increased significantly at a PP level of $\geq 64 \mathrm{~mm} \mathrm{Hg}$. All between-group differences in PP characteristics according to blood pressure status were significant $(\mathrm{p} \leq 0.05)$.

$0.10 \%$ for total and $0.12 \%$ for cardiovascular mortality, and $0.27,0.21$, and $0.09 \%$ for the composite cardiovascular endpoint, all cardiac events, and stroke, respectively. For most endpoints under study (fig. 2), with the exception of stroke, the lower boundary of the $95 \%$ CIs of the successive HRs crossed the reference line at levels ranging from $64 \mathrm{~mm} \mathrm{Hg}$ (composite cardiovascular endpoint) to $69 \mathrm{~mm} \mathrm{Hg}$ (total mortality and cardiac events).

Table 1 shows the prevalence of normotension, white-coat hypertension, masked hypertension, and sustained hypertension among younger ( $<60$ years) and older ( $\geq 60$ years) participants. In addition, table 1 shows that there were significant differences in PP according to the cross-classification based on conventional ( $\geq 140 / 90 \mathrm{~mm} \mathrm{Hg}$ ) and 24-hour ambulatory blood pressure ( $\geq 130 / 80 \mathrm{~mm} \mathrm{Hg}$ ). The prognostic value of these differences in PP remains to be established. Indeed, the prevalence of a PP $>64 \mathrm{~mm} \mathrm{Hg}$ only exceeded $10 \%$ in patients with sustained hypertension (table 1).

\section{International Database on Home Blood Pressure in Relation to Cardiovascular Outcome}

We analyzed the International Database on HOme blood pressure in relation to Cardiovascular Outcome (IDHOCO) data [22] following the same methods as described above for the IDACO study. In the 3,285 younger subjects, the median follow-up was 8.3 years. Over 32,671 person-years of follow-up, 149 participants died and 161 experienced a fatal or nonfatal cardiovascular complication. The cause of death was cardiovascular in 41 participants. The association between outcome and PP did not deviate significantly from log-linearity $(p \geq 0.092)$. Table 2 shows the standardized HRs associated with home mean blood pressure and home PP. When adjusted for cohort, sex, age, body mass index, smoking and drinking, serum cholesterol, home pulse rate, history of cardiovascular disease, diabetes mellitus, and antihypertensive treatment, the home PP significantly predicted all outcomes, except for fatal and nonfatal stroke. After further adjustment for mean arterial pressure, PP only predicted all-cause and cardiovascular mortality (table 2). The low number of events precluded an analysis by the deciles of the PP distribution in the younger participants. 
Gu et al.: Risk Associated with Pulse Pressure on Out-of-Office Blood Pressure Measurement

Table 2. Standardized HRs relating outcomes to home PP by age group

\begin{tabular}{|c|c|c|c|c|c|c|}
\hline & \multicolumn{3}{|c|}{ Age $<60$ years } & \multicolumn{3}{|c|}{ Age $\geq 60$ years } \\
\hline & events, $\mathrm{n}$ & mean blood pressure & PP & events, $n$ & mean blood pressure & PP \\
\hline \multicolumn{7}{|c|}{ Mortality } \\
\hline \multicolumn{7}{|c|}{ All causes } \\
\hline A & 149 & $1.24(1.01-1.51)^{*}$ & $1.28(1.08-1.52)^{* *}$ & 663 & $1.04(0.95-1.13)$ & $1.14(1.05-1.25)^{* *}$ \\
\hline FA & & $1.08(0.86-1.37)$ & $1.24(1.01-1.51)^{*}$ & & $0.96(0.86-1.06)$ & $1.17(1.06-1.30)^{* *}$ \\
\hline \multicolumn{7}{|c|}{ Cardiovascular } \\
\hline A & 41 & $1.44(0.98-2.10)$ & $1.56(1.15-2.11)^{* *}$ & 253 & $1.08(0.94-1.24)$ & $1.22(1.07-1.40)^{* *}$ \\
\hline FA & & $1.15(0.75-1.77)$ & $1.47(1.03-2.10)^{*}$ & & $0.96(0.82-1.14)$ & $1.25(1.06-1.47)^{* *}$ \\
\hline \multicolumn{7}{|c|}{ Fatal plus nonfatal events } \\
\hline \multicolumn{7}{|c|}{ All cardiovascular } \\
\hline $\mathrm{A}$ & 161 & $1.50(1.24-1.80)^{* * * *}$ & $1.34(1.15-1.56)^{* * * *}$ & 555 & $1.26(1.15-1.38)^{* * * *}$ & $1.25(1.14-1.36)^{* * * *}$ \\
\hline FA & & $1.35(1.09-1.68)^{* *}$ & $1.18(0.98-1.41)$ & & $1.18(1.06-1.32)^{* *}$ & $1.14(1.02-1.27)^{*}$ \\
\hline \multicolumn{7}{|c|}{ Cardiac } \\
\hline $\mathrm{A}$ & 90 & $1.66(1.31-2.10)^{* * * *}$ & $1.38(1.15-1.66)^{* * *}$ & 246 & $1.01(0.88-1.16)$ & $1.12(0.98-1.27)$ \\
\hline FA & & $1.50(1.12-2.00)^{* *}$ & $1.15(0.92-1.45)$ & & $0.91(0.77-1.09)$ & $1.18(1.00-1.39)$ \\
\hline \multicolumn{7}{|c|}{ Coronary } \\
\hline $\mathrm{A}$ & 76 & $1.54(1.20-2.00)^{* * *}$ & $1.26(1.03-1.55)^{*}$ & 175 & $1.03(0.87-1.21)$ & $1.15(0.99-1.34)$ \\
\hline FA & & $1.49(1.08-2.06)^{*}$ & $1.05(0.81-1.35)$ & & $0.90(0.73-1.11)$ & $1.22(1.00-1.49)^{*}$ \\
\hline \multicolumn{7}{|l|}{ Stroke } \\
\hline $\mathrm{A}$ & 73 & $1.25(0.94-1.68)$ & $1.31(1.01-1.71)^{*}$ & 320 & $1.51(1.34-1.70)^{* * * *}$ & $1.37(1.21-1.56)^{* * * *}$ \\
\hline FA & & $1.13(0.82-1.56)$ & $1.25(0.94-1.68)$ & & $1.42(1.23-1.63)^{* * * *}$ & $1.14(0.98-1.32)$ \\
\hline \multicolumn{7}{|c|}{$\begin{array}{l}\text { HRs, presented with } 95 \% \text { CIs, express the risk associated with a 1-SD increase in mean home blood pressure }(11.7 \text { and } 11.2 \mathrm{~mm} \mathrm{Hg} \\
\text { in subjects aged }<60 \text { years and } \geq 60 \text { years, respectively) or a 1-SD increase in home PP (8.8 and } 13.4 \mathrm{~mm} \text { Hg, respectively). All models } \\
\text { were stratified for cohort and adjusted for sex, age, body mass index, smoking and drinking, serum cholesterol, home pulse rate, } \\
\text { diabetes mellitus, history of cardiovascular disease, and antihypertensive treatment. Adjusted models (A) include either the mean } \\
\text { blood pressure or PP, while fully adjusted models (FA) include both mean blood pressure and PP in addition to the aforementioned } \\
\text { covariates. Significance of the HRs: }{ }^{*} p<0.05,{ }^{* *} p<0.01,{ }^{* * *} p<0.001 \text {, and }{ }^{* * *} p<0.0001 \text {. Reproduced with permission from Gu et } \\
\text { al. [19]. }\end{array}$} \\
\hline
\end{tabular}

In the 3,185 older subjects, the median follow-up was 8.2 years (5th-95th percentile interval, 7.2-16.8 years). Over 26,655 person-years of follow-up, 663 participants died and 555 experienced a fatal or nonfatal cardiovascular complication. The cause of death was cardiovascular in 253 participants. Considering fully adjusted models, the home PP predicted all of the endpoints ( $\mathrm{p} \leq 0.044)$, except for fatal combined with nonfatal cardiac events $(\mathrm{p}=$ $0.052)$ and stroke $(\mathrm{p}=0.083)$. The generalized $\mathrm{R}^{2}$ statistics for adding home PP as the predictor of outcome over and beyond mean arterial pressure was $\leq 0.20 \%$.

Figure 1 shows the multivariable-adjusted HRs for outcomes in the top decile of the distribution of home PP versus the average risk in all of the elderly subjects. The HRs reached statistical significance in the upper decile for total mortality, cardiovascular mortality, all cardiovascular events, all cardiac events, and all coronary events. The risk of stroke in the upper decile did not exceed the average risk among all elderly. PP in the 9th and top deciles of the distribution of home PP averaged 71.3 mm Hg (range, 67.8-75.9 mm Hg) and $84.9 \mathrm{~mm}$ Hg (range, 76.0-125.8 $\mathrm{mm} \mathrm{Hg}$ ), respectively.

\section{Interpretation}

The Seventh Report of the Joint National Committee on Prevention, Detection, Evaluation, and Treatment of High Blood Pressure [23] proposed that PP is only marginally stronger than systolic blood pressure for risk stratification in individuals aged $\geq 60$ years, and that for those aged $<60$ years, PP is not predictive. According to the 2007 European guideline [24], PP is a derived measure, which combines the imprecision of the original systolic and diastolic mea- 
Gu et al.: Risk Associated with Pulse Pressure on Out-of-Office Blood Pressure Measurement

surements. This guideline stated that, although levels of 50-55 mm Hg have been suggested, no practical cutoff values separating PP normality from abnormality are available. The 2013 European guideline [25] increased this threshold to $60 \mathrm{~mm}$ Hg without providing any justification. The IDACO analyses [19] established that for people aged $<60$ years, a 24-hour PP level of about $60 \mathrm{~mm} \mathrm{Hg}$ might be associated with increased risk, but that a safe threshold could not be established. Among the elderly participants, a 24-hour PP of about $76 \mathrm{~mm} \mathrm{Hg}$ was definitely associated with higher risk, and levels $<64 \mathrm{~mm} \mathrm{Hg}$ were probably safe. Using intra-arterial monitoring, Khattar et al. [26] observed that survival rates were highest among individuals aged $<60$ years, if the 24 -hour PP was $<70$, and lowest among elderly patients with a 24-hour PP of $\geq 70 \mathrm{~mm} \mathrm{Hg}$. To our knowledge, Khattar et al.'s [26] report is the only other study proposing an outcome-driven threshold for 24-hour PP. However, this article does not include any justification as to why $70 \mathrm{~mm} \mathrm{Hg}$ was chosen as the threshold in a dichotomized analysis. The results were based on an unadjusted Kaplan-Meier survival function analysis, and the study population consisted of patients with essential hypertension, in whom treatment had been withdrawn for 8 weeks [26]. All other proposals for PP thresholds relied on conventional blood pressure measurements. In analyses adjusted but not stratified for age, 2 studies [3, 9] derived a threshold from the 66th percentile of the PP distribution. Madhavan et al. [3] proposed a threshold of $63 \mathrm{~mm} \mathrm{Hg}$ based on the incidence of myocardial infarction in 2,207 hypertensive patients aged 55 years, and Borghi et al. [9] suggested a threshold of $67 \mathrm{~mm} \mathrm{Hg}$ based on the incidence of cardiovascular disease among 2,939 Italian patients (aged 14-84 years). Asmar et al. [27] derived a threshold of $65 \mathrm{~mm} \mathrm{Hg}$ from the mean PP plus 2 SDs in 61,724 French patients (aged 16-90 years). The IDHOCO analyses [22] established that, for patients aged $<60$ years, total and cardiovascular mortality were log-linearly associated with home PP, but that due to the small number of events, no outcome-driven threshold could be established. In the elderly, home PP predicted all endpoints with the exception of stroke, but the refinement of prognostication over and beyond traditional risk factors and the steady component of blood pressure was small. Among elderly, the threshold delineating an increased risk of death is around $68 \mathrm{~mm} \mathrm{Hg}$, and for fatal combined with nonfatal cardiovascular events it is $76 \mathrm{~mm} \mathrm{Hg}$.

\section{Conclusions}

After review of the available literature, we did a subject-level meta-analysis to derive outcome-driven thresholds for PP based on 24-hour ambulatory monitoring or self-reported blood pressure measured at home. All results are generalizable because they originate from 14 randomly recruited population samples, representing 13 countries and 3 continents. For subjects aged $<60$ years, irrespective of the measurement method, PP did not add to risk stratification. However, for those aged $\geq 60$ years, higher PP conferred an increased cardiovascular risk. However, while accounting for all covariables, a PP in the top decile of the distribution contributed $<0.3 \%$ to the overall risk among the elderly. The proposed thresholds are $\geq 70 \mathrm{~mm} \mathrm{Hg}$ for 24-hour PP and $76 \mathrm{~mm} \mathrm{Hg}$ for home PP. These observations could inform guidelines and be of help to clinicians in diagnosing and managing patients.

\section{Acknowledgments}

The European Union (HEALTH-2011.2.4.2-2-EU-MASCARA, HEALTH-F7-305507 HOMAGE and the European Research Council Advanced Researcher Grant 2011-294713-EPLORE), the Fonds voor Wetenschappelijk Onderzoek Vlaanderen, Ministry of the Flemish Community, Brussels, Belgium (G.0881.13 and G.0880.13), and the International Zinc and Lead Research Organization currently support the Studies Coordinating Centre in Leuven, Belgium. 
Gu et al.: Risk Associated with Pulse Pressure on Out-of-Office Blood Pressure Measurement

\section{Disclosure Statement}

The authors have no conflicts of interest to declare.

\section{References}

Staessen J, Amery A, Fagard R: Editorial review. Isolated systolic hypertension. J Hypertens 1990;8:393-405. Bangalore S, Messerli FH, Franklin SS, Mancia G, Champion A, Pepine CJ: Pulse pressure and risk of cardiovascular outcomes in patients with hypertension and coronary artery disease: an INternational VErapamil SR-trandolapril STudy (INVEST) analysis. Eur Heart J 2009;30:1395-1401.

-3 Madhavan S, Ooi WL, Cohen H, Alderman MH: Relation of pulse pressure and blood pressure reduction to the incidence of myocardial infarction. Hypertension 1994;23:395-401.

-4 Greenberg J: Antihypertensive treatment alters the predictive strength of pulse pressure and other blood pressure measures. Am J Hypertens 2005;18:1033-1039.

-5 Domanski MJ, Davis BR, Pfeffer MA, Kastantin M, Mitchell GF: Isolated systolic hypertension: prognostic information provided by pulse pressure. Hypertension 1999;34:375-380.

6 Liu JH, Chen CC, Wang SM, Chou CY, Liu YL, Kuo HL, et al: Association between pulse pressure and 30-month all-cause mortality in peritoneal dialysis patients. Am J Hypertens 2008;21:1318-1323.

7 Franklin SS, Larson MG, Khan SA, Wong ND, Leip EP, Kannel WB, et al: Does the relation of blood pressure to coronary heart disease change with aging? The Framingham Heart Study. Circulation 2001;103:1245-1249.

-8 Benetos A, Safar M, Rudnichi A, Smulyan H, Richard JL, Ducimetiere P, et al: Pulse pressure: a predictor of longterm cardiovascular mortality in a French male population. Hypertension 1997;30:1410-1415.

-9 Borghi C, Dormi A, Ambrosioni E, Gaddi A; Brisighella Heart Study Working Party: Relative role of systolic, diastolic and pulse pressure as risk factors for cardiovascular events in the Brisighella Heart Study. J Hypertens 2002;20:1737-1742.

10 Schram MT, Kostense PJ, van Dijk RAJM, Dekker JM, Nijpels G, Bouter LM, et al: Diabetes, pulse pressure and cardiovascular mortality: the Hoorn Study. J Hypertens 2002;20:1743-1751.

11 Glynn RJ, Chae CU, Guralnik JM, Taylor JO, Hennekens CH: Pulse pressure and mortality in older people. Arch Intern Med 2000;160:2765-2772.

12 Darne B, Girerd X, Safar M, Cambien F, Guize L: Pulsatile versus steady component of blood pressure: a crosssectional analysis and a prospective analysis on cardiovascular mortality. Hypertension 1989;13:392-400.

13 Lewington S, Clarke R, Qizilbash N, Peto R, Collins R; Prospective Studies Collaboration: Age-specific relevance of usual blood pressure to vascular mortality: a meta-analysis of individual data for one million adults in 61 prospective studies. Lancet 2002;360:1903-1913.

14 Domanski M, Mitchell G, Pfeffer M, Neaton JD, Norman J, Svendsen K, et al: Pulse pressure and cardiovascular disease-related mortality. JAMA 2002;287:2677-2683.

15 Miura K, Dyer AR, Greenland P, Daviglus ML, Hill MA, Liu K, et al: Pulse pressure compared with other blood pressure indexes in the prediction of 25-year cardiovascular and all-cause mortality rates. Hypertension 2001;38:232-237.

-16 Inoue R, Ohkubo T, Kikuya M, Metoki H, Asayama K, Kanno A, et al: Stroke risk of blood pressure indices determined by home blood pressure measurement: the Ohasama study. Stroke 2009;40:2859-2861.

-17 Inoue R, Ohkubo T, Kikuya M, Metoki H, Asayama K, Obara T, et al: Predicting stroke using 4 ambulatory blood pressure monitoring-derived blood pressure indices: the Ohasama Study. Hypertension 2006;48:877-882.

-18 Miura K, Nakagawa H, Ohashi Y, Harada A, Taguri M, Kushiro T, et al: Four blood pressure indexes and the risk of stroke and myocardial infarction in Japanese men and women. A meta-analysis of 16 cohort studies. Circulation 2009;119:1892-1898.

19 Gu YM, Thijs L, Li Y, Asayama K, Boggia J, Hansen TW, et al: Outcome-driven thresholds for ambulatory pulse pressure in 9938 participants recruited from 11 populations. Hypertension 2014;63:229-237.

20 Franklin SS, Gustin W, Wong ND, Larson MG, Weber MA, Kannel WB, et al: Hemodynamic patterns of agerelated changes in blood pressure. The Framingham Heart Study. Circulation 1997;96:308-315.

-21 Staessen JA, Thijs L, Fagard R, O’Brien ET, Clement D, de Leeuw PW, et al: Predicting cardiovascular risk using conventional vs ambulatory blood pressure in older patients with systolic hypertension. JAMA 1999;282: 539-546.

22 Aparicio LS, Thijs L, Asayama K, Barochiner J, Boggia J, Gu YM, et al: Reference frame for home pulse pressure based on cardiovascular risk in 6470 subjects from 5 populations. Hypertens Res 2014;37:672-678.

23 Chobanian AV, Bakris GL, Black HR, Cushman WC, Green LA, Izzo JL Jr, et al: Seventh report of the Joint National Committee on Prevention, Detection, Evaluation, and Treatment of High Blood Pressure. Hypertension 2003; 42:1206-1252.

24 Mancia G, De Backer G, Dominiczak A, Cifkova R, Fagard R, Germano G, etal: 2007 guidelines for the management of arterial hypertension: the Task Force for the Management of Arterial Hypertension of the European Society of Hypertension (ESH) and of the European Society of Cardiology (ESC). Eur Heart J 2007;28:1462-1536. 
25 Mancia G, Fagard R, Narkiewicz K, Redón J, Zanchetti A, Böhm M, et al: 2013 ESH/ESC guidelines for the management of arterial hypertension: the Task Force for the Management of Arterial Hypertension of the European Society of Hypertension (ESH) and of the European Society of Cardiology (ESC). Eur Heart J 2013; $34: 2159-2219$.

26 Khattar RS, Swales JD, Dore C, Senior R, Lahiri A: Effect of aging on the prognostic significance of ambulatory systolic, diastolic, and pulse pressure in essential hypertension. Circulation 2001;104:783-789.

27 Asmar R, Vol S, Brisac AM, Tichet J, Topouchian J: Reference values for clinic pulse pressure in a nonselected population. Am J Hypertens 2001;14:415-418. 